\title{
Third-party Reverse logistics platform and method Based on Bilateral Resource Integration
}

\author{
Hong Zhen Zheng ${ }^{1, a}$, Dian Hui $\mathrm{Chu}^{2}$ and Ming Shun Shao ${ }^{3}$ \\ ${ }^{123}$ Department of Computer Science \& Technology Harbin Institute of Technology Weihai, 264209, China
}

\begin{abstract}
Dispersion of reverse logistics resources makes it difficult to create relationships between demanders and providers, thereby the personalized demand for the construction of enterprise reverse logistics cannot be satisfied and the service quality cannot be guaranteed. Aiming at these problems, this paper presents a platform and method of enterprise reverse logistics based on bilateral resource integration (RLBRI). The method creates a third-party reverse logistics platform to accumulate a mass of reverse logistics demanders and providers together. And the platform integrates bilateral resources and acts as an intermediary to establish relationships between two sides. Through the platform, a complete and high-quality business chain for enterprise reverse logistics will be built efficiently. Finally put forward an effective strategy of non-defective reverse logistics depends on the integrity checking service provided by third-party logistics. By using this strategy it can short the distance of non-defective reverse transportation. Computational tests validate the strategy.
\end{abstract}

\section{Introduction}

There is an increasing trend toward sustainable and green supply chain design and management in today's business world. In terms of execution and practice, reverse supply chain management is an effective way for enterprises to achieve sustainability and become green and lean. Reverse supply chains deal with products that have reached the end of their life cycles or the ones returned by the final users. Furthermore, reverse supply chain management can reduce the negative environmental impacts of waste disposal and resource extraction, and reduce production costs. It considers a generic electronic product that can be remanufactured or recycled at the end of its life cycle to generate new profit. Amy Z. Zeng [6] explores a revenuesharing coordination mechanism which generate insights on how to manage an efficient consumer-retailer-manufacturer reverse supply chain, as well as on the feasibility of simplifying such a three-stage chain structure. More and more enterprises have recognized the importance of reverse logistics on enterprise's competitive advantages, ultimate issue of profitability, environment-friendly image and better consumer service [2,7]. However, reverse logistics is actually very involved and can be extremely complex, which severely constrains the development of the enterprise reverse logistics. BIRIS [4], a new service application mode designed by our lab ICES, is proposed for solving the difficulties to create relationships among a large number of suppliers and demanders and to guarantee the service quality. In this mode, a third-party platform was imported to accumulate a mass of customers and providers together, and it could collect customer resources to providers and integrate service resources to customers. At present, our laboratory has done some researches on BIRIS-based forward logistics which proves BIRIS can better solve the problems of logistics field. In addition, gathering and integrating reverse logistics resources reasonably, and building relationships between suppliers and demanders of the reverse logistics efficiently [3] are two key steps to establish enterprise reverse logistics. So this paper will combine BIRIS with reverse logistics to better serve the enterprise.

The rest of the paper is structured as follows. Section 2 is devoted to presenting the current status of enterprise reverse logistics and their problems. Section 3 proposes a third-party reverse logistics platform based on bilateral resource integration to build enterprise RL and outlines its core issues, business analysis, functional design and technical architecture. Section 4 presents five advantages of this platform. Section 5 gives an example about RL of an electronic company on the platform. Finally a conclusion and future research is outlined.

\footnotetext{
a Hongzhen Zheng: hithongzhen@163.com
} 


\section{Current operation modes and industry practices of enterprise reverse logistics}

\subsection{Current operation modes of enterprise reverse logistics}

Enterprise reverse logistics generally involves events like collection, classification, transportation and disposing of goods. These goods are moved backward from consumers to enterprises. In general, there are three common operating modes of enterprise reverse logistics [2,7].

(1) Self-managed. Enterprises take the whole responsibilities of investment, cost and administration under procedures of collection, classification, transportation and disposal. The enterprise must have its own reverse logistics management systems, recycling facilities and technology, related personnel, etc. However, goods in reverse logistics are relatively low value and the volumes in reverse logistics are much less than in foreword logistics. So it is difficult for an individual enterprise to run a self-managed reverse logistic to reach economies of scale.

(2) Alliance of enterprises. Enterprises alliance is built by several companies who produce same or similar products. They could share facilities on recycling, reusing, disposal, repairing or remanufacturing and therefore reduce the investment. Compared with the former, the alliance of enterprises reduces the cost and makes the risk shared between companies. But these two operation modes above both require independent reverse logistics management system more or less, which is not under the control of those business-oriented enterprises. In addition, most of the enterprises are unable to handle the complex networking necessary to have an efficient reverse logistics links such as collection, classification, transportation and warehousing.

(3) Outsourcing. Enterprises outsource all or part of their reverse logistics to the third-party logistics service providers (3PL). Alliance of 3PLs [5] serve similar industries or have complementary businesses has been built to reduce costs and risk and expand the economies of scale. This mode is undoubtedly the best choice for enterprises to build reverse logistics. However, from a long-term perspective, there are some disadvantages. Firstly, not all of the 3PLs can provide a complete and professional reverse logistics businesses, and then available selections for enterprises are even fewer. Secondly, during the cooperation, it is hard for enterprises to get feedbacks quickly and even difficult to monitor the process of reverse logistics. Finally, with the rapid development of forward logistics, a large majority of 3PLs are unwilling to devote all of the resources to reverse logistics.

A construction method of enterprise reverse logistics based on bilateral resource integration proposed next will not only inherits the advantages of these three operation modes, but also avoids and improves their drawbacks to some extent.

\subsection{Current operation industry practices reverse logistics}

Most of the online store in order to improve the competitiveness provides "7/15 days no reason to return", "free shipping insurance", "free postage return" and other services like that. Ghazaleh Tajik [1] proposed a method improves the purchase rate as well as the returns, the additional reverse logistics process brings great pressure to the third party logistics (3PLs) providers. Most free-return policy supports unconditional return within the limited time, thus consumers may return the product due to its appearance, model or other personal reasons. This is called non-defective return which plays an important role in reverse logistics. And the following is the conventional process of non-defective return:

Step 1 Consumer $B$ apply for non-defective returns

Step 2 Seller A allows return request and notify the return address addr 1

Step 3 Consumer B sent goods to addr1 through 3PLs

Step 4 Seller $A$ receives the goods and checks the integrity

Step 5 Seller A confirms refund

Step 6 Consumer C place an order

Step 7 Seller A sends goods to C's address addr2

There is twice cargo transportation in that process. Step 3: From consumer B to seller A, Step 7: From seller A to consumer $\mathrm{C}$. The second time transportation is the forward logistics' process, the first time transportation is to check the integrity of the goods (assume that all non-defective return items will be sold again), so if the integrity check work was transferred to the logistics business, the second time transportation can be omitted.

\section{Third-party reverse logistics platform based on bilateral resource integration}

In order to overcome the existing drawbacks and break the bottlenecks of enterprise reverse logistics development, the idea of BIRIS [4] was applied to reverse logistics.

As a result, this paper proposes to build a third-party reverse logistics platform based on bilateral resource integration in which the third-party reverse logistics providers (3PRL) provide one or more parts of the reverse logistics links and enterprises are demanders to build their own reverse logistics business chains. Core issues of enterprise reverse logistics based on bilateral resource integration need to be solved are as follows:

(1) How to solve the difficulties to create relationships among a large number of reverse logistics providers and demanders.

(2) 3PRLs, as individuals, can only support a small part of links on reverse logistics. But after the effective integration of their resources, an all-around and personalized reverse logistics business links can serve demanders. 
(3) Collections of reverse logistics demands from enterprises should be provided to reverse logistics providers.

(4) Monitoring the whole process of reverse logistics from both providers' side and demanders' side will improve the service quality of reverse logistics and the value of reverse logistics.

\subsection{Business analysis of the third-party reverse logistics platform}

The third-party reverse logistics platform consists of three main parts: reverse logistics demanders, reverse logistics providers and third-party centre. A large amount of demanders and providers connect to the platform. The former express their personalized demands, the latter provide a variety of heterogeneous resources, and the platform acts as an intermediary to establish relationships between two sides. As it is shown in Fig.1.

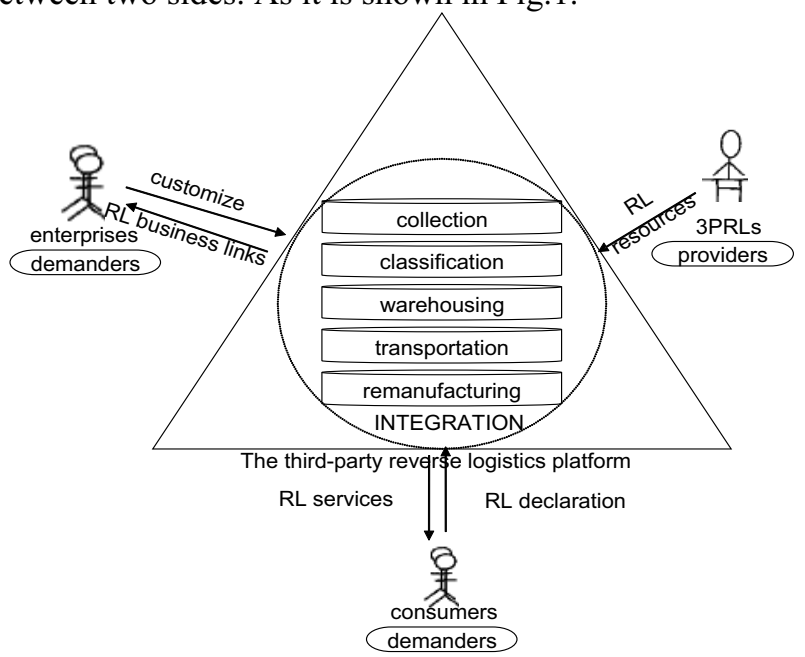

Fig.1 Business analysis of third-party reverse logistics service platform

The core businesses of reverse logistics are collection, classification, warehousing, transportation, and remanufacturing, and these functional links are all provided by registered 3PRLs. 3PRLs is composed by many kinds of agencies. Like agencies of collection, classification, warehousing or transportation and agencies of recycling, remanufacturing or maintenance. All these providers can provide all or just a small part of the functional businesses in reverse logistics. Finally, the platform takes a management of large numbers of decentralized reverse logistics resources, then integrates and publishes them.

As an enterprise-type reverse logistics demander, you need to first describe your products and choose which part of the reverse logistics functional links you want to subscribe. As your own original services, you can choose to connect it to the platform through an interface and publish it or not. After the collection of the enterprise-type demander's personalized needs, the platform will recommend an existing integrated business chain of reverse logistics to the enterprise. Only accepted schemes audited by platform will build up suitable reverse logistics business chains. At the same time, the enterprise can publish its business chains to seek corporate allies. In addition, a reverse logistics platform without terminal products consumers likes a smart machine without power unit. Therefore, in order to design a perfect third-party reverse logistics platform, it is crucial to consider how to make product consumers participate into the platform. The reverse behaviours of consumers, like product scrapped, maintenance, unconditional return or product trial, are the sources of reverse logistics. Through the platform, recycling sites for specific products have already been announced by enterprises. For example, a tablet purchased by a consumer has some quality problems. First of all, the consumer logs on to the platform, enters the name of the company and the SN of the product. Then the platform will show a list of recycling sites at the consumer's city. Consumers can send the product to the recycling site. Finally, based on the invoice number of reverse logistics, consumers can query or monitor the dealing progress of products at home through the platform.

Under the bilateral resources integration, the platform not only establishes better relationships between providers and demanders, but also gives more chances to small enterprises even 3PRLs to develop their reverse logistics.

\subsection{Functional design of the third-party reverse logistics platform}

Combined with the business analysis described, we design a functional diagram of the platform. It is shown in Fig.2.

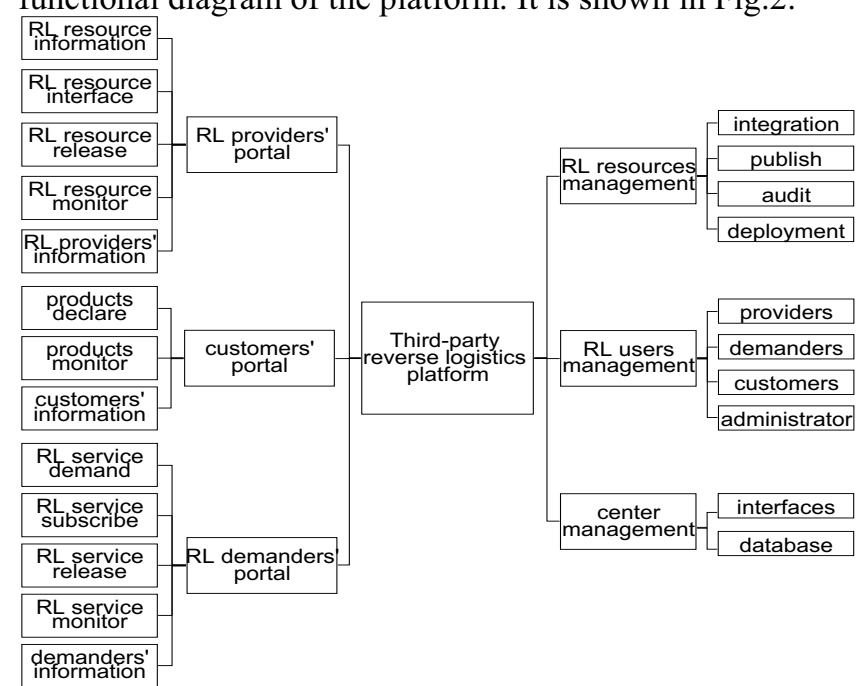

Fig.2 Functional design of third-party reverse logistics service platform

The third-party reverse logistics platform has two main parts, management and portal. The management part consists of resources management, user management and 
centre management. And portal part consists of providers' portal, demanders' portal and consumers' portal.

(1) Management module. First, we must clearly ensure the users of the platform and preserve their information. Providers, demanders, consumers, and administrators are listed in the "user management" module. Then the platform has the responsibility to manage all the resources provided by providers, like integrating the resources, publishing the integrated business links, auditing the demanders' schemes and then deploying resources for them. Finally, in order to maintain the stability, the platform needs to check the interfaces linked by the demanders' or providers' business systems and maintain the database.

(2) Portal module. The platform provides three portals to our three main users, including providers, enterprise-type demanders and product consumers. Providers have access to register reverse logistic resources which includes resource information and resource interfaces, publish and monitor their resources. Second, demanders have access to subscribe reverse logistics business links, publish and monitor them as well. Finally, terminal product consumers could surf the platform, declare the recycling requirements and monitor the process.

\subsection{Technical architecture of third-party reverse logistics platform}

Based on the idea of bilateral resource integration, the thirdparty reverse logistics platform needs to consider the coordination and interoperability between reverse logistics resource and reverse logistics businesses with the specific information technology, as shown in Fig.3.

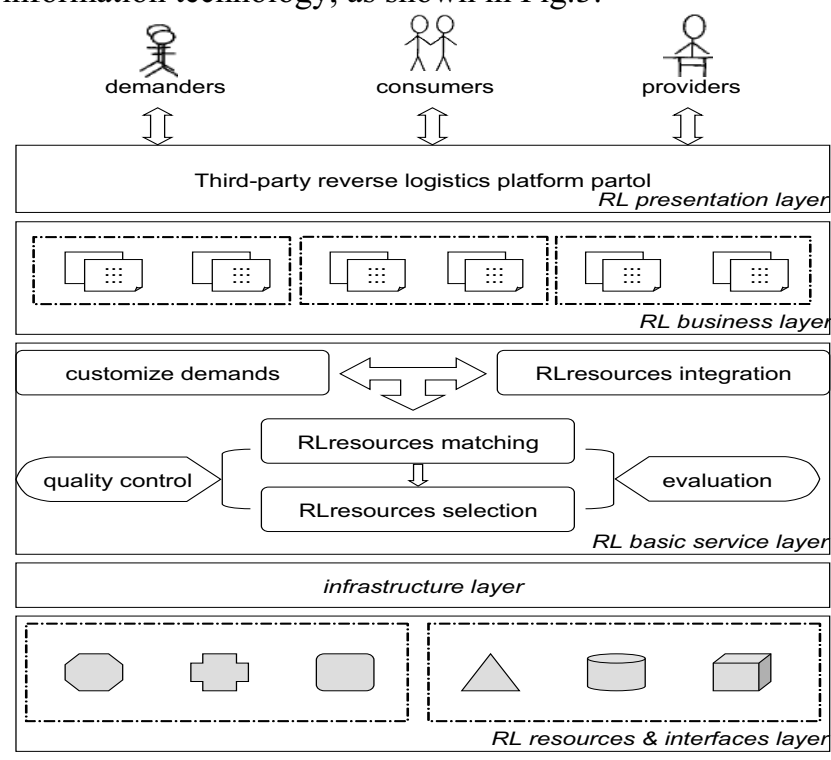

Fig.3 Technical architecture of third-party reverse logistics service platform

The platform is divided into five levels. They are RL presentation layer, RL business layer, RL basic service layer, RL infrastructure layer and resource/interface layer. This is a typical SOA-based architecture. The detailed description of a certain technology can be found in literature [4].

\subsection{Method of enterprise reverse logistics, RLBRI}

In order to build high-quality reverse logistics for enterprises in a quicker and more efficient way, this paper proposes to design a third-party reverse logistics platform. And its five advantages need to be outlined.

(1) Integrating decentralized reverse logistics resources to virtual resources. In the traditional cooperation between enterprises alliances and 3PL alliances, there are only a limited number of 3PLs for enterprises to choose from. In addition, in the traditional 3PL alliances, most 3PLs are professional reverse logistics providers which can provide most parts even all parts of reverse logistics businesses. But in the platform proposed in this paper, providers with only one part of the reverse logistics businesses can also register their resources. The platform collects decentralized reverse logistics resources and then integrates them to virtual resources with higher added value.

(2) An adaptive solution of enterprise reverse logistics is supported. In the forward logistics, except that some goods need special treatment like frozen food and chemicals, most goods are suitable for standard processes. While in the reverse logistics, situations are more complicated. The solutions of reverse logistics always change among different types of products or even sometimes among the same type of products. Therefore, simply relying on the platform to integrate resources and publish functional links is not flexible and applicable enough. So our platform allows enterprise-type demander to customize its own reverse logistics businesses according to its products. This complete personalized reverse logistics business chain is also a new chain for the platform.

(3) Value addition among providers, demanders and consumers. Providers in the platform will make a better management of their resources. They can get more businesses, reach economies of scale and make more profits.

Enterprise-type demanders will customize their reverse logistics through the platform. Under the proper regulation, the reverse logistics of enterprise works fluently and gains more competitive advantages, more businesses, more profits and better environment-friendly image.

(4) It is beneficial for the combination between forward logistics and reverse logistics. Providers in our platform maybe only support a small part of functional links in reverse logistics, which is relatively easy for them to combine businesses between forward logistics and reverse logistics.

(5) Credit accumulation and evaluation between providers and demanders makes a higher-quality enterprise reverse logistics. In the process of reverse logistics, demanders and providers can choose each other based on their credit data. Credit data can be obtained from two ways. 
One asks the two sides to score each other. Another asks the platform to monitor some key points of processes in reverse logistics. In the end, the credit history will be used to recommend, select, supply or set the price of the reverse logistics functional links.

\subsection{RL of typical electronic company on the platform}

Electronic product recovery has always been an issue of concern. The construction process of electronic company $\mathrm{RL}$ through the platform is described as follow:

(1) Enterprises register to the platform. Our third-party reverse logistics platform has already accumulated a mass of reverse logistics providers which provide reverse logistics resources. Company A deals in office computer products, such as desktop computer, server computer, laptop computer is going to build its own reverse logistics business. As the first step, company A has to register to the platform, describes its business and puts forward its individual demands.

(2) Establishing reverse logistics business chain. As company A is a typical electronic company, it can not only choose an existing business chain about electronic products recovery recommended by the platform, but also select functional units

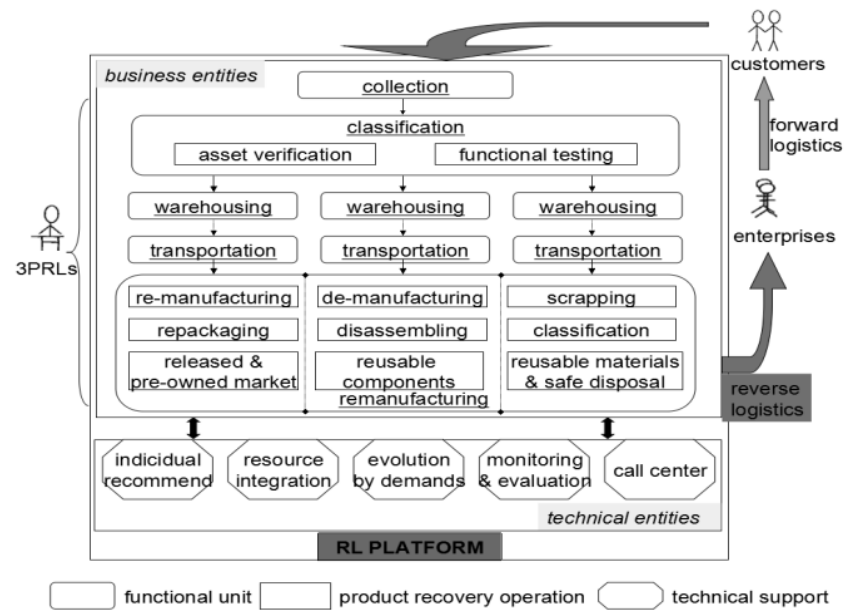

Fig.4 RL business chain of electronic company

Separately according to its' budget or special situations. The RL business chain of electronic company $A$ is illustrated in Fig.4. The returned products are accumulated firstly in the process of collection. Products are either for repairmen or for returning. The process of assets verification is to ensure products are in good and ordered conditions and a bill for cost of replacing missing or nonfunctional items will be sent to the consumers. By functional testing, the returned products are classified into three categories, i.e., re-manufacturing, de-manufacturing and scrapping. Warehousing and transportation are two necessary links.
Functional links mentioned above are all supported by registered RL providers of the platform. Furthermore, resources integration, business construction and process monitoring are supported by RL platform. The platform collects and monitors the data generated in each step of execution process.

\section{Non-defective reverse logistics}

Section 2 has described the process of non-defective reverse logistics; Step 3: From consumer B to seller A, Step 7: From seller A to consumer C. The second time transportation is a common forward logistics process which we won't be taken into consider in this paper. And the significance of the first time transportation is to check the integrity of the goods (assume that all non-defective return items will be sold again), so if the integrity check work was transferred to third party logistics' business, the second time transportation can be omitted.

Fig5 is the simulation map of forward and reverse logistics process. Star icon represents seller's address (assume delivery address correspond with return address).

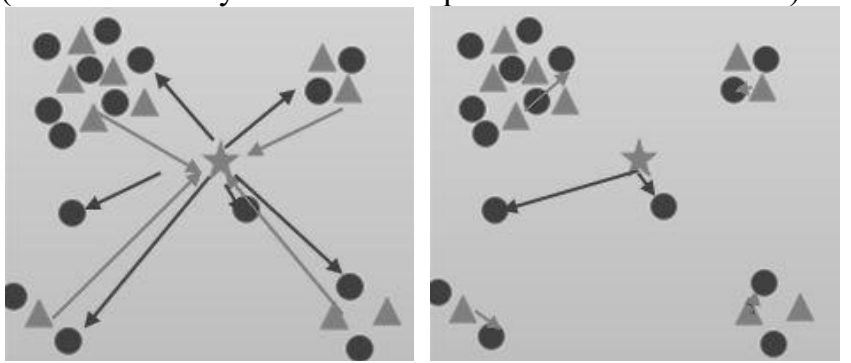

Fig. 5 The Original and Optimized forward and reverse logistics simulation map.

Based on the above analysis, in this paper we will introduce a new strategy for non-defective reverse logistics. This strategy optimized the flow of non-defective returns process which has been described in section2. After the optimization of the strategy, Step 3 and Step 7 in section2 can be integrated into third-party logistics providers send goods to add2. Fig5 left was changed to Fig5 right. The arrow indicates reverse returns are sent from consumer to consumer. The total transportation length in Optimized forward and reverse logistics is shorter than half of the length in Original, thereby reduced transportation costs and waste.

\section{Computational tests}

In this section optimized transportation distance is compared with previous transportation distance which was described in Section 4 and Section 2. The sales data of Ushape pillow is used as test data, for the sake of authenticity we use the real data provided by Alibaba. And this data comes from Taobao Index. Consumers' geographical distribution screenshot of U-shape pillow (from 2013-11-01 to 2014-04-26) is show as Fig6, circles represents the 
consumer position and the size of these circle represents the number of consumers who bought the U-shape pillow.

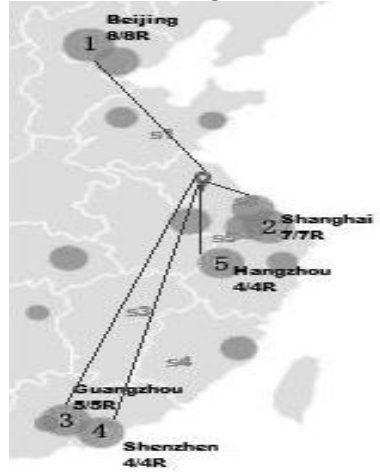

Fig.6 Consumer geographical distribution of U-shape pillow.

For seller, a return process and a delivery process is a circle unit. In Fig6, the figures show that in every 100 sold U-shape pillows there are 8 pillows has shipped to Beijing, 7 to Shanghai, 5 to Guangzhou, 4 to Shenzhen and 4 to Hangzhou. $S_{\text {trotal }}=S_{\text {tirnarid }}+S_{\text {return }}$ represents the straight-line distance between seller address with Beijing, Shanghai, and Guangzhou and so on. The total transportation distance in one circle unit is defined as below:

$$
\begin{aligned}
& S_{\text {forward }}=8 \times s_{1}+7 \times s_{2}+5 \times s_{3}+4 \times s_{4}+4 \times s_{5} \\
& S_{\text {return }}=R \times S_{\text {forward }}, 0 \leq R \leq 1 \\
& \mathrm{~s}_{1}=1040 \mathrm{KM}, \mathrm{s}_{2}=310 \mathrm{KM}, \mathrm{s}_{3}=1378 \mathrm{KM}, \mathrm{s}_{4}=1383 \mathrm{KM}, \mathrm{s}_{5}=270 \mathrm{KM}
\end{aligned}
$$

$(5-1)$ is the distance of forward logistics, (5-2) is the distance of reverse logistics. The data in (5-3) comes from Google Map. Based on section4, the optimized total transportation distance in one circle unit is defined as follows:

$$
\begin{aligned}
& S_{\text {forward }}^{\prime}=(1-R) \times S_{\text {forward }} \\
& S_{\text {return }}^{\prime}=R \times\left(8 \times l_{1}+7 l_{2}+5 l_{3}+4 l_{4}+4 l_{5}\right)
\end{aligned}
$$$$
l_{1}, l_{2}, l_{3}, l_{4}, l_{5} \text { Represents the average distance between }
$$

any two points [4-5] within a city, as the general northsouth length and east-west length is not greater than $100 \mathrm{KM}$, so $l=50 \mathrm{~km}$ can be used instead of $l_{1}, l_{2}, l_{3}, l_{4}, l_{5}$.

Then the final result is as below:

$$
S_{\text {total }}^{\prime} / S_{\text {total }} \approx 0.908, R=0.1
$$

(5-6) means if the return rate is 0.1 then the sellers' transportation expenses will cutting to former's 90\%. For consumers, the total transportation distance is cutting from $s_{1}, s_{2}, s_{3}, s_{4}, s_{5}$ to $l_{1}, l_{2}, l_{3}, l_{4}, l_{5}$. Then the result is:

$$
\frac{1_{1}}{\mathrm{~s}_{1}}=0.048, \frac{1_{2}}{\mathrm{~s}_{2}}=0.161, \frac{1_{3}}{\mathrm{~s}_{3}}=0.036, \frac{1_{4}}{\mathrm{~s}_{4}}=0.036, \frac{1_{5}}{\mathrm{~s}_{5}}=0.185
$$

That means consumer's transportation expenses can be cutting to former's $3.6 \% \sim 19 \%$ by using the strategy introduced in section4.

\section{Conclusion}

In this paper, we propose a construction platform and method of enterprise reverse logistics based on bilateral resource integration and a third-party platform is imported in it. The platform collects decentralized reverse logistics resources and then integrates them to virtual resources with higher added value. It accumulates a mass of demanders and providers together and creates relationships between them quickly. Through the platform, enterprises could create their own service chains of reverse logistics with low cost, low risk, high profit, direct feedback and real-time monitoring according to their individual demands. Last, this paper proposes an effective strategy, which can choose another customer's delivery address as consumer's return address to shorten the distance of return transportation. Simulation and computation test show that by using the proposed strategy, the consumer's return transportation expenses can be cut to former's $3.6 \% \sim 19 \%$.

The idea of bilateral resource integration is a new concept proposed in recent years. And most of the researches are about to combine it with forward logistics in a certain field. Further research would be on field of the combination between forward logistics and reverse logistics through the platform.

\section{Acknowledgment}

The paper is supported by National Science and Technology Support Program (2014BAF07B02) and Natural fund (ZR2015FM006).

\section{References}

[1] Ghazaleh Tajik, Amir Hossein Azadnia, “A Hybrid Fuzzy MCDM Approach for Sustainable Third-Party Reverse Logistics Provider Selection," Advanced Materials Research Vol. 845, (2014) pp.521-526.

[2] Hernandez-Hernandez, Helga J.Design of multi-product / multi-period closed-loop reverse logistics network using a genetic algorithm. Source: IEEE Proceedings Symposium on Computational Intelligence in Production and Logistics Systems, January 12, (2015), pp 40-47.

[3] Li-xia $\mathrm{Su}$, Zhao-hua Wang and $\mathrm{Li} \mathrm{Su}$, "The impact of information sharing on reverse logistics performance based on Canonical Correlation Analysis," Information Management, Innovation Management and Industrial Engineering (ICIII), (2012), pp 167-170.

[4] WANG Zhong-jie and XU Xiao-fei, "Bilateral resource integration service mode for value innovation," Computer Integrated Manufacturing Systems, Vol. 15, No.11, (2009), pp 2216-2225.

[5] Weidong Guo, "Selection Model of Third-party Reverse Logistics Service Providers Under supply chain management," Control and Decision Conference (CCDC), (2012), pp 1761-1764.

[6] Zeng, Amy Z Coordination mechanisms for a three-stage reverse supply chain to increase profitable returns. Source: Naval Research Logistics, February, v 60, n 1, (2013), pp31-45. 
[7] Zhao Jian guang, "Basic research on reverse logistics implemented by enterprise," Mechatronic Science, Electric Engineering and Computer (MEC), (2011), pp 807-810. 